\title{
Pain experience, pain management strategies and satisfaction of hospitalized trauma patients in Indonesia
}

\author{
Deya Prastika, Luppana Kitrungrote, Jintana Damkliang \\ Faculty of Nursing, Prince of Songkla University, Songkhla, Thailand
}

Received: July 29, 2017

DOI: $10.5430 /$ jnep.v8n1p79
Accepted: August 26, 2017

Online Published: September 15, 2017

\begin{abstract}
Although trauma is a common cause of greater pain and interference on daily activities, little is known about pain experience, pain management strategies and pain management outcomes in hospitalized trauma patients in Indonesia. This descriptive study aimed (1) to assess the pain experience, (2) to describe pain management strategies, and (3) to describe satisfaction with pain management conducted by healthcare providers as perceived by trauma patients. A total of 154 hospitalized trauma patients from a teaching hospital in Indonesia were recruited from January to March 2016. Data were analyzed using descriptive and inferential statistics. The study found that most of the hospitalized trauma patients had single extremity fractures $(56.49 \%)$ and mild head injury $(20.13 \%)$. They have experienced a mild to moderate level of pain intensity and pain interference during the first three days of admission. These pain intensity and pain interference levels were found to be significantly decreased from the first to the third day. The pain management strategies often used by the healthcare providers were showing interest and asking about pain, assessing the outcomes after receiving analgesic drugs, and giving information about pain. The pain management strategies often used by patients were praying (86.36\%), slow and deep breathing (77.27\%), and reciting Dzikir (meditation) (68.18\%). Patients reported that performing Dzikir and praying were the effective strategies to reduce their pain. The patients rated moderate to high levels of satisfaction with pain management conducted by healthcare providers. Therefore, combinations analgesic drugs with praying and performing Dzikir related to cultural contexts are crucial to alleviate pain among hospitalized trauma patients in Indonesia.
\end{abstract}

Key Words: Pain, Pain management, Satisfaction, Trauma

\section{INTRODUCTION}

The incidence of trauma has been high and is considered to increase through the years. ${ }^{[1]}$ In Indonesia, the incidence of trauma from traffic accidents accounts for approximately 1.3 million victims every year. ${ }^{[2]}$ The increased number of trauma patients is becoming a public health concern, ${ }^{[2]}$ therefore, a study in this population is pivotal.

Trauma patients often deal with greater pain intensity, ${ }^{[3]}$ therefore, appropriate pain management is needed to reduce the negative effects on a patient's physical and psychological health ${ }^{[4]}$ However, trauma patients have reported concerns in pain management such as healthcare providers' lack of patients' pain assessment and their limited knowledge regarding pain management. ${ }^{[5-7]}$ Patients' satisfaction with healthcare providers' pain management showed controversial findings. ${ }^{[3,8]}$

*Correspondence: Deya Prastika; Email: prastika.dy@ gmail.com; Address: Faculty of Nursing, Prince of Songkla University, Songkhla, Thailand. 
The differences of sociocultural contexts among countries have been recognized as one of the influencing factors on how a person perceives pain experience, pain management, and pain outcomes. ${ }^{[9]}$ Research on pain, pain management, and satisfaction in hospitalized trauma patients in Indonesia is limited. The purpose of this present study was to describe the pain experience, pain management strategies, and satisfaction perceived by hospitalized trauma patients. Such knowledge will be helpful to provide basic information for healthcare providers in providing proper pain management relating to a Muslim's way of life-based in the Indonesian context.

\section{Literature review}

Pain in trauma has been confirmed by Western studies as patients with orthopedic or musculoskeletal injuries. The patients in these studies reported moderate to severe pain intensity as assessed by the brief pain inventory during their hospital stay and before discharge. ${ }^{[3,10]}$ Also, patients with burn injuries reported moderate to high pain levels, especially during a routine procedure such as wound care. ${ }^{[11,12]}$ The pain intensity interfered with patients' daily life activities including general activity, walking, and sleeping. ${ }^{[3,7,10-14]}$

Previous studies showed that healthcare providers used pharmacological and/or non-pharmacological interventions to reduce acute pain. For instance, pharmacological management included the use of Fentanyl and Diclofenac. Fentanyl appeared to be superior to the other analgesics (e.g., Tramadol) in relieving moderate to severe pain for patients with extremity trauma. ${ }^{[15]}$ A meta-analysis study showed that the administration of Diclofenac had been reported as the best result to reduce pain in patients with musculoskeletal injuries compared to another topical non-steroid anti-inflammatory drug. ${ }^{[16]}$ Moreover, healthcare providers and patients manage pain based on their knowledge, beliefs, and experiences. Several alternative methods, including using heat and cold compresses, ${ }^{[17]}$ and giving information about pain, ${ }^{[18]}$ have been used successfully to reduce pain after trauma. A study revealed that a majority of burn patients used avoiding movement and passive coping methods such as avoiding thinking about the pain and tolerating the pain. ${ }^{[6]}$

Satisfaction with pain management is an important measure of the quality of care. ${ }^{[6]}$ Several previous studies showed that trauma patients reported high satisfaction with pain management. ${ }^{[3,19]}$ The orthopedic injury patients were satisfied with all dimensions in pain medication including time of medication to work, amount of pain relief provided, duration of pain relief provided, a form of medication, the frequency of medication and the amount of medication. ${ }^{[3]}$ This finding is consistent with a study that found that burn injury patients rated high satisfaction with pain medication. ${ }^{[19]}$ However, patients' satisfaction of pain management provided by either the physicians or the nurses had been reported as different results, those patients were more satisfied with pain management provided by the physicians than by the nurses. ${ }^{[3,20]}$ Conversely, patients reported higher satisfaction with the nurses rather than physicians. ${ }^{[21]}$ The issue is whether a high rating is clouded by the fact that satisfaction is a subjective view that involves expectations of care and attitudes and belief about pain management. ${ }^{[22]}$

\section{Methods}

\subsection{Sample and setting}

A descriptive study design was carried out after approval was obtained from the Research Ethics Committee of a teaching hospital. This hospital is in West Java Province, Indonesia. Annually, an estimated 1,225 trauma patients are admitted to the surgical wards in this hospital. Therefore, the sample size was $10 \%$ of the population per the proportional estimation of a sample for a descriptive study. ${ }^{[23]}$ The inclusion criteria for these patients were (1) aged 18 years and over, (2) good consciousness, (3) no psychiatric disorders and chronic pain from other diseases, and (4) understand the Indonesian language. All patients participated in this study gave written informed consent.

\subsection{Questionnaires}

\subsubsection{Patient's data form}

This form consists of two parts. First, personal information consists of age, gender, religion, education level, and expectation of pain management conducted by physicians and nurses. Second, health and illness-related data consists of medical diagnosis, pain medication, and treatments.

\subsubsection{Brief pain inventory}

The Brief Pain Inventory (BPI) Indonesian version was used to measure pain experience including pain intensity and pain interference during the first three days of hospital admission. ${ }^{[9]}$ Pain intensity was assessed over the past 24 hours; pain right now, pain at worst, pain at least, and pain on average. Pain interference consisted of general activity, mood, working, walking, relation with others, sleep, and enjoyment of life. In this study, the item of working in the pain interference scale was excluded because the patients were admitted to a hospital. ${ }^{[3]}$ The numeric scale used for both pain intensity and pain interference ranged from " 0 " no pain and does not interfere to "10" pain as bad as you imagine and completely interfere. ${ }^{[9]}$ The reliability of the BPI showed that Cronbach's alpha of pain intensity was .94 and Cronbach's alpha of pain interference was .87. The interpretation of pain intensity and pain interference level was classified into three 
categories, including mild (1.00-3.99), moderate (4.00-6.99), and severe (7.00-10.00). ${ }^{[9]}$

\subsubsection{Pain management questionnaire}

The Pain Management Questionnaire (PMQ) was developed by the researchers based on the literature review to assess the patients' perceptions regarding the pain management implemented by the physicians, nurses, and patients during the first three days of hospital admission. There were 8 options for pain management strategies used by physicians (PMQphysicians) and 11 options used by nurses (PMQ-nurses). Moreover, 11 options for pain management strategies were used by patients. The patients could choose more than one option. In addition, an open-ended question was provided at the end of the PMQ to report other strategies that were not available in the list of options. The frequency and effectiveness of patients' pain management methods were explained. The content of the PMQ was validated by health professional experts in pain and trauma. The content validity index showed the result of .90 , indicating that this instrument was valid to measure the variables in this study. ${ }^{[24]}$

\subsubsection{Satisfaction with pain management questionnaire}

Although previous validated patients' satisfaction questionnaires, for example, Patients Satisfaction Questionnaire (PSQ) and Patient Treatment Satisfaction Scale (PTSS) are available for use in this study, there are several considerations in using these tools in this study such as these tools focus on the patient's satisfaction with pain medication and there are too many items that might increase the burden of administration. To measure patients' satisfaction with pain management including pain medications and alternative pain management methods conducted by physicians and nurses, the Satisfaction with Pain Management Questionnaire (SPMQ) was developed by the researchers. The patients rated their satisfaction with pain management conducted by physicians and nurses. The SPMQ consists of five scales; very satisfied (5), satisfied (4), slightly satisfied (3), dissatisfied (2) and very dissatisfied (1) ${ }^{[3]}$ The interpretation is based on mean scores and is categorized into five levels as follows ${ }^{[24]} 1.00-1.49$ (very low), 1.50-2.49 (low), 2.50-3.49 (moderate), 3.50-4.49 (high), and 4.50-5.00 (very high). The SPMQ was validated by experts in pain and trauma. The Cronbach's alpha showed the result of .73 for the SPMQ overall (.71 for the SPMQ-physicians and .73 for the SPMQ-nurses).

\subsection{Procedures}

After authorization was obtained from the Research Ethics Committee of the teaching hospital, the researcher (PD) started to collect data at the surgical ward. The researcher was introduced by a nurse to a potential participant who met the inclusion criteria in the first day of hospital admission.
The researcher then explained the objectives of the study. After obtaining the written informed consent, participants were asked to fill out the Personal Data Form and the BPI, the PMQ, and the SPMQ. If the participants were unable to read or write due to the injury, the researcher assisted them to read the items of questionnaires and asked verbally to choose the response. The Personal Data Form was distributed on the first day after hospital admission, while the BPI was continuously distributed on the first, the second, and the third day. Finally, the PMQ and SPMQ were distributed on the third day.

\subsection{Data analysis}

Collected data were analyzed using descriptive and inferential statistics. Descriptive statistics were used to present the study data, including pain intensity, pain interference, pain management, and satisfaction with pain management. Inferential statistics, an ANOVA repeated measure was used to measure the differences in pain intensity and pain interference in the first three days after admission. Moreover, the simple content analysis was used to analyze the data from the open-ended questions of pain management.

\section{Results}

\subsection{Patients' characteristics}

Overall, 172 patients participated in the study, 18 cases were excluded because of incomplete data due to patients' discharge, leaving 154 patients for the analysis. The average age of the patients was $37.42(\mathrm{SD}=10.79)$. Most of the patients were male (75.32\%), Islamic (85.71\%) and $33.42 \%$ of the patients had an education level of senior high school. Patients were diagnosed with single extremity fractures (i.e., leg, hand, clavicle) $(56.49 \%)$, mild traumatic brain injury $(20.13 \%)$, burn $(9.01 \%)$, and other injuries (i.e., strain, abdominal stab wound) (14.37\%). Most of the patients $(89.02 \%)$ received medical procedures including wound dressing, splint, sling, and skin or skeletal traction. Approximately $10.98 \%$ of the patients received surgery. During the first, second, and third day of admission, the patients received opioid (i.e., Tramadol, Fentanyl) as $76.62 \%, 77.27 \%$, and $79.22 \%$, respectively. The patients also received non-steroid anti-inflammatory drugs (i.e., Paracetamol, Ketorolac) as $45.45 \%, 44.81 \%$, and $34.42 \%$, respectively. Majority of the patients $(95.16 \%)$ had high to very high expectation level regarding pain management conducted by physicians, and $60.39 \%$ had high to very high expectation level regarding pain management conducted by nurses.

\subsection{Pain experience of hospitalized trauma patients}

Overall, the mean scores of pain intensity of the hospitalized trauma patients during the first three days after admission 
were at a mild to moderate level. The average pain was at a moderate level on the first day, and then decreased to a mild level on the second and the third day $(\mathrm{M}=4.13, \mathrm{SD}=1.21$; $\mathrm{M}=3.81, \mathrm{SD}=1.01 ; \mathrm{M}=3.40, \mathrm{SD}=1.03$, respectively) Furthermore, the ANOVA repeated measure test revealed statistically significant differences when comparing the scores of pain at worst, at least, average and right now on the first, second, and third day $(\mathrm{F}(2,306)=199.14, p<.001 ; \mathrm{F}(2$, $306)=48.90, p<.001 ; \mathrm{F}(2,306)=116.58, p<.001 ; \mathrm{F}(2$, $306)=198.27, p<.001$, respectively) (see Figure 1$)$.

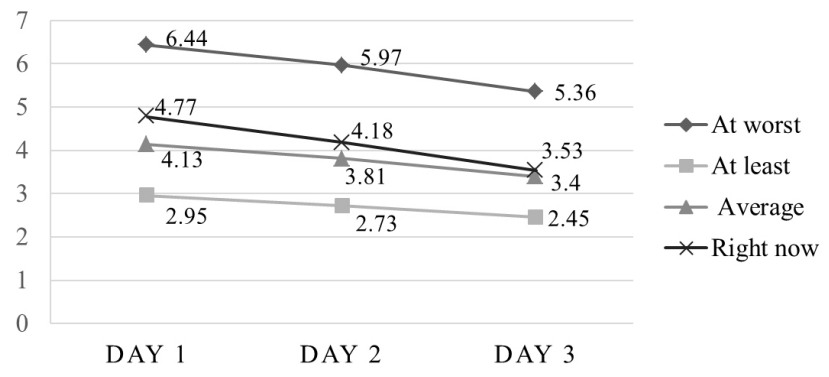

Figure 1. The Pain Intensity at Worst, at Least, Average, and Right Now Perceived by Hospitalized Trauma Patients in the First Three Days After Admission $(\mathrm{N}=154)$

Overall, the mean scores of pain interference were mild to moderate level in the first three days after admission. Walking was reported as the most interfered $(\mathrm{M}=4.75, \mathrm{SD}=$ $1.61)$, followed by general activity $(\mathrm{M}=4.38, \mathrm{SD}=1.58)$, and sleep $(\mathrm{M}=4.13, \mathrm{SD}=1.19)$. Furthermore, the mean scores of pain interference on walking, general activity, and sleep were highest on the first day and showed a statistically significant decrease over the three days $(\mathrm{F}(2,306)=79.31, p$ $<.001 ; \mathrm{F}(2,306)=1114.55, p<.001 ; \mathrm{F}(2,306)=200.46, p$ $<.001$, respectively) (see Figure 2).

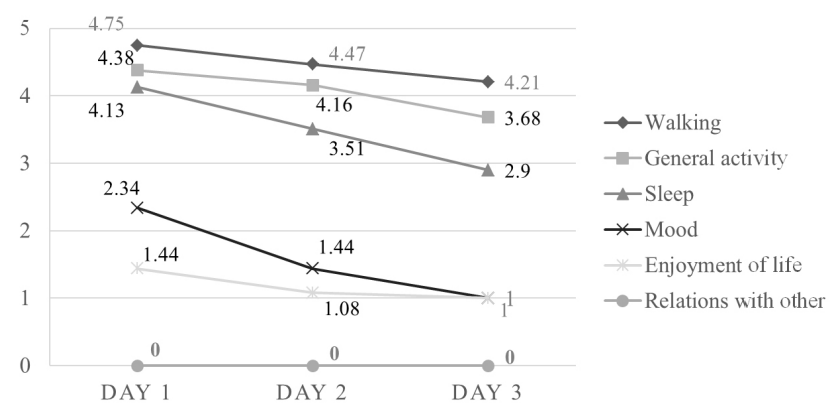

Figure 2. The Pain Interference of Hospitalized Trauma Patients in the First Three Days After Admission $(\mathrm{N}=154)$

\subsection{Pain management strategies used by patients}

In Table 1, the hospitalized trauma patients used several pain management strategies by themselves in the first three days after admissions. The first ranked strategy used was praying, which was conducted by $86.36 \%$ of the patients. Slow and deep breathing (72.27\%) and Dzikir (meditation) $(68.18 \%)$ ranked as the second and the third. Regarding the frequency of using pain management methods, praying (57.14\%), listening to music (38.89\%), and reciting Dzikir (36.19\%) were reported by patients that they conducted these strategies at most times, respectively.

Furthermore, the patients evaluated the pain management strategies at a slightly to fully effective level. The top three ranked pain management strategies that were reported as effective by patients were (1) performing Dzikir (80.00\%), (2) listening to music $(77.78 \%)$, and (3) praying $(69.92 \%)$ (see Table 1).

\subsection{Pain management conducted by physicians and nurses and patients' satisfaction with pain manage- ment}

The patients reported that they received pain management strategies from physicians in the first three days after admission including showing interest and asking about pain symptom (98.05\%), assessing the outcomes after receiving analgesic drug (94.16\%), and giving information about pain $(72.73 \%)$. For the pain management strategies conducted by the nurses, patients reported that showing interest and asking about pain symptoms were perceived as the most frequent $(97.40 \%)$. These were followed by giving information about pain $(88.96 \%)$ and assessing the outcomes after receiving analgesic drugs $(88.96 \%$ ) (see Table 2).

Furthermore, the patients rated moderate to high levels of satisfaction with pain management implemented by both the physicians and nurses (see Table 2). Patients rated a high level of satisfaction to two of the eight pain management strategies given by physicians. These were giving encouragement and showing understanding and sympathy $(\mathrm{M}=$ 3.68, $\mathrm{SD}=0.81$ ) and showing interest and asking about pain symptom $(\mathrm{M}=3.57, \mathrm{SD}=0.65)$. Meanwhile, there were 5 out of 11 pain management strategies implemented by nurses rated as highly satisfying by patients. These were giving assistance with different activities while feeling pain $(\mathrm{M}=$ $4.07, \mathrm{SD}=0.80)$, giving information about pain $(\mathrm{M}=3.89$, $\mathrm{SD}=0.71$ ), giving encouragement and showing understanding and sympathy $(\mathrm{M}=3.72, \mathrm{SD}=0.69)$, showing interest and asking about pain symptoms $(\mathrm{M}=3.71, \mathrm{SD}=0.59)$, and giving an explanation to relieve anxiety $(\mathrm{M}=3.53, \mathrm{SD}=$ 0.71) (see Table 2).

\section{Discussion}

This study found that the pain experiences including the averages of pain intensity and pain interference among hospitalized trauma patients were at a mild to moderate level. 
Conversely, Western findings showed a moderate to severe level of pain intensity. ${ }^{[3,11,13]}$ The pain interfered the most with walking, general activity, and sleeping. Obviously, since most of the patients had long bone fractures, it is not surprising that pain mostly interfered with physical functioning. ${ }^{[3,7,11]}$ Furthermore, both of pain intensity and pain interference found statistically different on mean score reduction during three days after hospital admission. This may be be- cause most of the patients in the present study had minor injuries such as single extremity fractures $(56.49 \%)$ and mild head injury (20.13\%), received medical and surgical procedures to immobilize the injured areas and reduce pain. ${ }^{[25]}$ Moreover, the combination of pharmacological (i.e., opioid, NSAIDs) and non-pharmacological methods conducted by physicians, nurses, and patients were adequately effective to the relief pain in trauma. ${ }^{[26]}$

Table 1. The Frequency and effectiveness of Pain Management Strategies Conducted and Perceived by Hospitalized Trauma Patients in the First Three Days After Admission ( $\mathrm{N}=154)$

\begin{tabular}{|c|c|c|c|c|c|c|}
\hline \multirow[b]{2}{*}{ Strategies } & \multicolumn{3}{|c|}{ Frequency $n *(\%)$} & \multicolumn{3}{|c|}{ Effectiveness n (\%) } \\
\hline & $\begin{array}{l}\text { Rare } \\
n^{*}(\%)\end{array}$ & $\begin{array}{l}\text { Sometimes } \\
n^{*}(\%)\end{array}$ & $\begin{array}{l}\text { Most times } \\
n^{*}(\%)\end{array}$ & $\begin{array}{l}N / A \\
n^{*}(\%)\end{array}$ & $\begin{array}{l}\text { Slightly effective } \\
n^{*}(\%)\end{array}$ & $\begin{array}{l}\text { Fully effective } \\
n^{*}(\%)\end{array}$ \\
\hline $\begin{array}{l}\text { Praying } \\
n=133(86.36 \%)\end{array}$ & - & $57(42.86)$ & $76(57.14)$ & $40(30.08)$ & - & $93(69.92)$ \\
\hline $\begin{array}{l}\text { Slow and deep breathing } \\
n=119(77.27 \%)\end{array}$ & 17 (14.29) & $102(85.71)$ & - & 22 (18.49) & $30(25.21)$ & 67 (56.30) \\
\hline $\begin{array}{l}\text { Dzikir** } \\
n=105(68.18 \%)\end{array}$ & - & 67 (63.81) & 38 (36.19) & $21(20.00)$ & - & $84(80.00)$ \\
\hline $\begin{array}{l}\text { Trying to tolerate } \\
n=65(42.21 \%)\end{array}$ & $11(16.92)$ & $45(69.23)$ & $9(13.85)$ & $65(100.00)$ & - & - \\
\hline $\begin{array}{l}\text { Talking with others } \\
n=57(37.01 \%)\end{array}$ & $23(40.35)$ & 34 (59.65) & - & 18 (31.58) & $21(36.84)$ & 18 (31.58) \\
\hline $\begin{array}{l}\text { Listening to music } \\
\mathrm{n}=54(35.06 \%)\end{array}$ & $11(20.37)$ & $22(40.74)$ & 21 (38.89) & $4(7.41)$ & $8(14.81)$ & $42(77.78)$ \\
\hline $\begin{array}{l}\text { Thinking pleasant thoughts } \\
n=44(28.57 \%)\end{array}$ & 30 (68.18) & $14(31.82)$ & - & 21 (47.73) & $23(52.27)$ & - \\
\hline $\begin{array}{l}\text { Asking for information } \\
n=36(23.38 \%)\end{array}$ & $36(100.00)$ & - & - & 15 (41.67) & $21(58.33)$ & - \\
\hline $\begin{array}{l}\text { Positioning } \\
n=34(22.08 \%)\end{array}$ & $21(61.76)$ & $13(38.24)$ & - & $11(32.35)$ & 7 (20.59) & $16(47.06)$ \\
\hline $\begin{array}{l}\text { Reading } \\
\mathrm{n}=27(17.53 \%)\end{array}$ & 24 (88.89) & 3 (11.11) & - & $21(77.78)$ & $6(22.22)$ & - \\
\hline $\begin{array}{l}\text { Reporting pain to nurses } \\
n=26(16.88 \%)\end{array}$ & $26(100.00)$ & - & - & $26(100.00)$ & - & - \\
\hline $\begin{array}{l}\text { Stroking near injured areas } \\
n=22(14.29 \%)\end{array}$ & $22(100.00)$ & - & - & $22(100.00)$ & - & - \\
\hline
\end{tabular}

Note. $^{*}=$ Each patient used more than one strategy. ${ }^{* *}=$ Dzikir is reciting the name of God for Muslim people. N/A = No answer.

Praying, reciting Dzikir, and slow and deep breathing (SDB) were non-pharmacological pain management strategies that used by most of the patients in this study. In particular, praying and performing Dzikir are a spiritual aspect that is personal concern relating to the belief about pain and its relief comes from God (Allah). ${ }^{[27]}$ This is consistent with a Muslim's way of life in Indonesia because praying is required five times a day and Dzikir is reciting the name of Allah. These strategies were rated high effective level by most of the patients because they resulted in the distraction effect and helped the patients to accept their pain. ${ }^{[28]}$
This result is different from previous studies that found that trauma patients used heat and cold compresses, ${ }^{[17]}$ avoidance of thinking about pain and movement and pain tolerance. ${ }^{[6]}$ In addition, the patients reported that they performed SDB because they wanted to relax their body and reduce the tension from nursing or medical procedures. Similarly, a study found that SDB is effective in reducing the pain in patients with burn injury during dressing changes. ${ }^{[29]}$

In addition, the top three pain management methods that most of the hospitalized trauma patients received from physicians and nurses were possibly influenced by the pain management 
guideline implemented in this teaching hospital. According to the guideline, it is noted that pain is the fifth vital sign and needs to be frequently recorded. ${ }^{[30]}$ Therefore, it is necessary for physicians, nurses, and medical and nursing students to assess and reassess a pain and to perform the educational intervention to improve patients' knowledge about pain. A previous study supported this finding described that a pain management standard is effective for improving the quality of pain reduction, while an absence of standard results in inadequate pain management. ${ }^{[31]}$

Table 2. Frequency and Percentage of hospitalized trauma patients who received pain management strategies by physicians and nurses in the first three days after admission and patients' satisfaction with pain management $(\mathrm{N}=154)$

\begin{tabular}{|c|c|c|c|}
\hline Strategies & $n *$ & $\%$ & Satisfaction $M(S D)$ \\
\hline \multicolumn{4}{|c|}{ Pain Management Strategies Conducted by Physicians } \\
\hline 1) Showing interest and asking about pain symptom & 151 & 98.05 & $3.57(0.65)$ \\
\hline 2) Assessing the outcomes after receiving analgesic drugs & 145 & 94.16 & $3.28(0.57)$ \\
\hline 3) Giving information about pain & 112 & 72.73 & $3.47(0.70)$ \\
\hline 4) Giving encouragement and showing understanding and sympathy & 75 & 48.70 & $3.68(0.81)$ \\
\hline 5) Giving an explanation to relieve anxiety & 65 & 42.21 & $3.37(0.76)$ \\
\hline 6) Giving advice on alternative strategies to reduce pain & 38 & 24.68 & $3.21(0.81)$ \\
\hline 7) Giving advice to ask for medication when feeling pain & 17 & 11.04 & $3.12(0.60)$ \\
\hline 8) Prescribing medication during pain & 1 & 0.65 & $3.00(0.00)$ \\
\hline \multicolumn{4}{|l|}{ Pain Management Strategies Conducted by Nurses } \\
\hline Showing interest and asking about pain symptoms & 150 & 97.40 & $3.71(0.59)$ \\
\hline Giving information about pain & 137 & 88.96 & $3.89(0.71)$ \\
\hline Assessing the outcomes after receiving analgesic drugs & 137 & 88.96 & $3.30(0.59)$ \\
\hline Giving assistance with different activities while feeling pain & 112 & 72.73 & $4.07(0.80)$ \\
\hline Giving an explanation to relieve anxiety & 98 & 63.64 & $3.53(0.71)$ \\
\hline Giving encouragement and showing understanding and sympathy & 87 & 56.55 & $3.72(0.69)$ \\
\hline Giving advice to think pleasant thoughts & 84 & 54.55 & $3.40(0.69)$ \\
\hline Giving advice to report to the nurse when feeling pain & 54 & 35.06 & $3.30(0.69)$ \\
\hline Giving advice on how to support the injured areas during activities & 44 & 28.57 & $3.30(0.70)$ \\
\hline Giving advice to read or talk with others & 22 & 14.29 & $3.18(0.73)$ \\
\hline Giving advice to change the attitude for pain reduction & 12 & 7.79 & $2.83(0.58)$ \\
\hline
\end{tabular}

*Each patient received more than one pain management strategy.

Similar findings have been found in previous studies in trauma. ${ }^{[3,20,21]}$ This present study found that the hospitalized trauma patients rated moderate to high levels of satisfaction with the pain management strategies implemented by both the physicians and the nurses when they had pain at mild to moderate level during three days after admission. This may be because the patients in the present study had high expectations toward pain management conducted by the physicians and the nurses, and their needs were fulfilled. For example, the physicians and the nurses gave encouragement, showed understanding and sympathy, demonstrated interest and asked about pain symptom, and provided information about pain. These non-pharmacological strategies made the patients feel that frequent communication implied that the physicians and nurses were concerned about them. Understanding about patients' situation contributes to higher satisfaction. ${ }^{[20]}$ Moreover, giving assistances with different activities while the patients were feeling pain conducted by nurses improves patient satisfaction with pain management. This was supported by a previous study which noted that patients' satisfaction could be achieved through consistent care and obtaining what the patients needed and listened to what they said during hospitalization. ${ }^{[32]}$ Similarly, most patients were satisfied or very satisfied with pain management from healthcare provider, regardless of their pain intensity score. ${ }^{[20]}$

\section{Conclusion}

This study reveals that hospitalized trauma patients reported mild to moderate pain intensity and pain interference during the first three days of admission. The comparison of pain intensity including pain right now, pain at worst, pain at least, 
and average pain were significantly decreased from the first to the third day. Patients reported most pain interference with walking, general activity, and sleep, and these pain interference levels were found to be significantly decreased from the first to the third day. To relieve pain from trauma, both pharmacological and non-pharmacological pain management strategies (e.g., opioids, NSAIDs, praying, SDB, Dzikir) were implemented by physicians, nurses and patients themselves related to the guideline and religious practices. Furthermore, the patients were satisfied with pain management provided by healthcare providers.

The findings of this study are useful for healthcare providers to place more concern on pain in hospitalized trauma patients by using a combination of pharmacological and nonpharmacological methods. Improvement in the quality of pain management is related to the guidelines and religious practice. Praying and performing Dzikir (meditation) are possibly supplement methods to relieve trauma pain in Muslim patients. Furthermore, healthcare providers should show understanding and sympathy, provide information on how to relieve pain and encouragement, and give assistance with activities during patients' feeling pain to improve their satisfaction with pain management.

There is a limitation that should be considered when interpreting the study findings. This present study was conducted at a single site so the generalizability of the results to other hospitals may be limited. Thus, the replication of this study with larger sample sizes and other settings is needed.

\section{ACKNOWLEDGements}

This study was supported by Thailand's Education Hub for ASEAN Countries (TEH-AC). We thank the Graduate School and Faculty of Nursing, Prince of Songkla University, Thailand; Hasan Sadikin General Hospital, Indonesia; and all the participants of this study.

\section{CONFlicts OF INTEREST Disclosure}

The authors declare that there is no conflict of interest.

\section{REFERENCES}

[1] Injuries a violence the facts. World Health Organization [2014; cited 2015]. Aavailable form: http: //www.who.int/violence_injury_prevention/media /news/2015/Injury_violence_facts_2014/en/

[2] Injury prevention [internet]. World Health Organization [2015; cited 2015]. Available form: http://www. searo.who.int/indonesi a/areas/noncommunicable_disease/en/

[3] Archer KR, Castillo RC, Wegener ST, et al. Pain and satisfaction in hospitalized trauma patients: the importance of self-efficacy and psychological distress. Journal of Trauma Acute Care Surgery. 2012; 72(4): 1068-77. PMid:22491629 https ://doi .org/10.1097/TA .0b013e3182452df5

[4] Gordon DB, Polomano RC, Pellino TA, et al. Revised American Pain Society Patient Outcome Questionnaire (APS-POQ-R) for quality improvement of pain management in hospitalized adults: preliminary psychometric evaluation. Journal of Pain. 2010; 11(11): 1172-86. PMid:20400379 https://doi.org/10.1016/j.jpain. 2010.0 2.012

[5] Balakrishnan S, Jhaj R, Raj V. Inadequate pain relief for patients with trauma: A cause for concern? Journal of Pharmacology and Pharmacotherapeutics. 2013; 4(4): 281-2. PMid:24250205 https://doi.org/10.4103/0976-500X.119714

[6] Wong EM, Chan SW. The pain experience and beliefs of Chinese patients who have sustained a traumatic limb fracture. International Emergency Nursing. 2008; 16(2): 80-7. PMid:18519058 https://doi.org/10.1016/j.ienj . 2008.02.002

[7] Yuxiang L, Lingjun $\mathrm{Z}, \mathrm{Lu} \mathrm{T}$, et al. Burn patients' experience of pain management: a qualitative study. Burns. 2012; 38(2): 180-6. PMid:22079543 https://doi .org/10.1016/j . burns . 2011.0 9.006

[8] Hayes K, Gordon DB. Delivering quality pain management: the challenge for nurses. AORN Journal. 2015; 101(3): 327-37.
PMid:25707725 https://doi.org/10.1016/j.aorn.2014.11 .019

[9] Dewi SE, Petpichetchian W, Songwathana P. Comparison of pain experiences between Javanese and Batak patients undergoing major surgery in Medan, Indonesia. Songklanagarind Medical Journal. 2007; 25(4): 247-58.

[10] Rosenbloom BN, Khan S, Mccartney C, et al. Systematic review of persistent pain and psychological outcomes following traumatic musculoskeletal injury. Journal of Pain Research. 2013; 6: 39-51. PMid:23357964 https://doi .org/10.2147/JPR. S38878

[11] Andrews RM, Browne AL, Wood F, et al. Predictors of patient satisfaction with pain management and improvement 3 months after burn injury. Journal of Pain Research. 2012; 33(3): 442-52. https://doi.org/10.1097/BCR.0b013e31823359ee

[12] De Jong AE, Bremer M, Hofland HW, et al. The visual analogue thermometer and the graphic numeric rating scale: A comparison of self-report instruments for pain measurement in adults with burns. Burns. 2015; 41(2): 333-40. PMid:25262546 https ://doi .org/ $10.1016 / \mathrm{j}$. burns .2014 .07 .002

[13] Platts-mills TF, Burke GF, Lee YM, et al. Pain and interference of pain with function and mood in elderly adults involved in a motor vehicle collision: a pilot study. Experimental Aging Research. 2012; 38(3): 330-43. PMid:22540386 https://doi.org/10.1080/03 61073X.2012.672139

[14] Varni JW, Stucky BD, Thissen D, et al. PROMIS Pediatric Pain Interference Scale: an item response theory analysis of the pediatric pain item bank. Journal of Pain. 2010; 11(11): 1109-19. PMid:20627819 https://doi.org/10.1016/j.jpain.2010.02.005

[15] Kariman H, Majidi A, Amini A, et al. Nitrous oxide/oxygen compared with fentanyl in reducing pain among adults with isolated extremity trauma: a randomized trial. Emergency Medicine Australasia. 2011; 23(6): 761-8. PMid:22151676 https : //doi.org/10.1 $111 / j .1742-6723.2011 .01447 . x$ 
[16] Rogers NV, Rowland K. An alternative to oral NSAIDs for acute musculoskeletal injuries. Journal of Family Practice. 2011; 60(3): 147-8. PMid:21369556

[17] Garra G, Singer AJ, Leno R, et al. Heat or cold packs for neck and back strain: a randomized controlled trial of efficacy. Academic Emergency Medicine. 2010; 17(5): 484-9. PMid:20536800 https://doi.org/10.1111/j.1553-2712.2010.00735.x

[18] Wong EM, Chan SW, Chair SY. Effectiveness of an educational intervention on levels of pain, anxiety and self-efficacy for patients with musculoskeletal trauma. Journal of Advance Nursing. 2010; 66(5): 1120-31. PMid:20337801 https://doi.org/10.1111/j . 1365-2648.2010.05273.x

[19] Browne AL, Andrews R, Schug SA, et al. Persistent pain outcomes and patient satisfaction with pain management after burn injury. The Clinical Journal of Pain. 2011; 27(2): 136-45. PMid:21268301 https://doi.org/10.1097/AJP.0b013e3181f7f9bb

[20] Phillips S, Gift M, Gelot S, et al. Assessing the relationship between the level of pain control and patient satisfaction. Journal of Pain Research. 2013; 6: 683-9. PMid:24049457

[21] Wikehult B, Kildal M, Willebrand M. Patient satisfaction with burn care 1-6 years after injury. burns. 2008; 34(6): 783-90 PMid:18378086 https ://doi.org/10.1016/j.burns.2007.1 1.001

[22] Thompson AG, Suñol R. Expectations as determinants of patient satisfaction: concepts, theory and evidence. International Journal for Quality in Health Care. 1995; 7(2): 127-41. PMid:7655809 https://doi.org/10.1093/intqhc/7.2.127

[23] Singchangchai P, Khumpalikit S, Nasae T. Nursing research: Principle and process (2nd ed). Sonkhla; Thailand: Faculty of Nursing, Prince of Songkla University.
[24] Polit DF, Beck CT. Nursing research: Generating and assessing evidence for nursing practice. Philadelphia; USA: Lippincott Williams \& Wilkins; 2008.

[25] Boyd AS, Benjamin HJ, Asplund C. Splints and casts: indications and methods. American family physician. 2009; 80(5). PMid: 19725490

[26] de Castro RJ, Leal PC, Sakata RK. Pain management in burn patients. Brazilian Journal of Anesthesiology. 2013; 63(1): 149-58. PMid:24565098 https://doi.org/10.1016/j.bjane.2012.0 2.003

[27] Unruh AM. Spirituality, religion, and pain. Canadian Journal of Nursing Research. 2007; 39(2): 66-86. PMid:17679586

[28] Wachholtz AB, Pearce MJ, Koenig H. Exploring the relationship between spirituality, coping, and pain. Journal of Behavioral Medicine. 2007; 30(4): 311-8. PMid:17541817 https://doi.org/10.100 7/s10865-007-9114-7

[29] Park E, Oh H, Kim T. The effects of relaxation breathing on procedural pain and anxiety during burn care. Burns. 2013; 39(6): 1101-6. PMid:23375536 https ://doi .org/10.1016/j.burns . 2013.0 1.006

[30] Hasan Sadikin General Hospital. Panduan penanganan nyeri di rumah sakit Hasan Sadikin [Hospital pain management guideline of Hasan Sadikin General Hospital]. Bandung: Hasan Sadikin General Hospital; 2014.

[31] Carr EC, Meredith P, Chumbley G, et al. Pain: a quality of care issue during patients' admission to hospital. Journal of Advance Nursing. 2014; 70(6): 1391-403. PMid:24224703 https ://doi.org/10.1 $111 /$ jan. 12301

[32] Kahn SA, Iannuzzi JC, Stassen NA, et al. Measuring satisfaction: factors that drive hospital consumer assessment of healthcare providers and systems survey responses in a trauma and acute care surgery population. American Journal of Surgery. 2015; 81(5): 537-43. 